\title{
Variations on a theme-singing as an epileptic automatism
}

\author{
H Meierkord, S Shorvon
}

\begin{abstract}
$A$ case report giving the clinical and EEG details of a patient with right temporal lobe epilepsy in whom singing was the predominant feature of the automatism.
\end{abstract}

"Music is nothing else but wild sounds civilised into time and tune" (Thomas Fuller, Worthies of England 1662).

Negative or positive musical phenomena in humans may result from lesions of various parts of the brain. Amusia in the absence of aphasia for instance has been reported following right hemispheric lesions ${ }^{12}$ and the inability to sing has been noted during transient inactivation of the non-dominant hemisphere. ${ }^{3}$ Musical hallucinations may occur in deafness ${ }^{4}$ or result from brainstem ${ }^{5}$ or frontal lesions ${ }^{6}$ and may also occur in seizures originating from either hemisphere. ${ }^{7}$ Musical hallucinations may also be elicited by electrical stimulation of various temporal regions ${ }^{8}$ but overt singing has never been elicited, and has to our knowledge not been reported during spontaneous epileptic seizures.

We describe a patient with complex partial seizures arising in the right temporal lobe in which singing was the major feature of the automatism, and discuss aspects of musicality and its anatomical localisation.

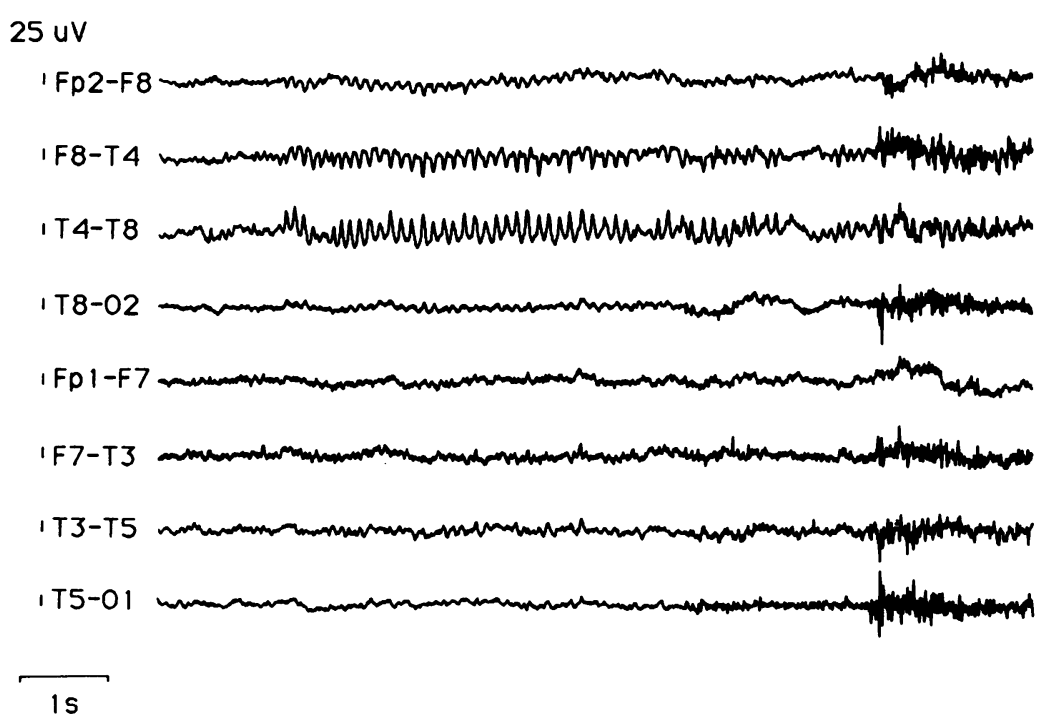

Figure 1 The EEG recorded between clinical attacks, showing an intermittent abnormality in the right mid-temporal region characterised by bursts of rhythmic $8 \mathrm{~Hz}$ activity lasting for about 6 seconds (time constant: 0.3 seconds, $\mathrm{HF} 70 \mathrm{~Hz}$ ). No clinical accompaniment was seen with this EEG abnormality.

\section{Case history}

A 48 year old right handed patient was admitted to The National Hospital for Neurology and Neurosurgery. Pregnancy, birth and development were normal and there was no family history of neurological disease. At the age of 11 , he developed attacks consisting of staring and loss of consciousness. He was put on phenytoin and these episodes had stopped by the age of 13 . Two years later the medication was stopped and he remained seizure free until the age of 22 when the episodes restarted. A further remission occurred between the ages of 29 and 46 years. The fits then recurred and at the time of admission he was having four to six episodes a day. The patient could not recall a warning but he had noticed that the attacks usually happened in states of drowsiness. He was of average education, there was no background of musicality and although interested in music he had no special education and was not an active musician.

The general and neurological examinations were normal. Full blood count, biochemistry and repeated CT scans were normal. The interictal EEG (fig 1) in between clinical attacks showed an intermittent abnormality in the right mid temporal region. This occurred in intervals of about one to two minutes and consisted of an $8 \mathrm{~Hz}$ discharge lasting about six seconds. The discharge was easily recognisable against a background activity of low amplitude.

On video EEG-telemetry four similar episodes were recorded. On each occasion he awoke from light sleep. He bent slightly forward and stiffened his arms and to a lesser extent his legs. Then there was some axial stiffening and breathing was interrupted in inspiration for 10-15 seconds. He then suddenly relaxed and sang a few bars of a blueslike song for 10-15 seconds. This was followed by either fiddling with his clothing or rubbing his face for 5-7 seconds. The duration of the episodes varied between 30 and 40 seconds each. He was unable to recall what had happened during the attacks. On each occasion the "musical production" was different. The accompanying EEG showed a stereotyped pattern with gradual build-up of rhythmical bilateral slow wave activity of increasing amplitude and decreasing frequency over approximately 7 seconds (fig 2). This was followed by flattening of the record. The patient started singing approximately at the end of the rhythmical slow wave discharge. The transcription of his "musical 


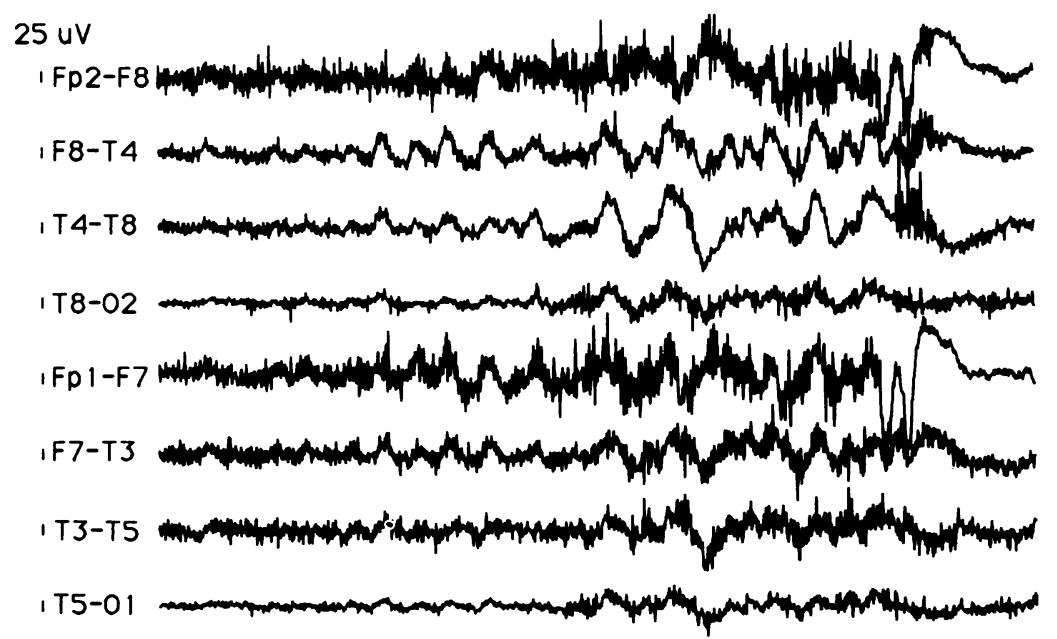

15

Figure 2 The ictal EEG onset, showing a stereotyped build up of rhythmical bilateral slow wave activity, of increasing amplitude and decreasing frequency, over approximately 7 seconds, followed by flattening. There is an eye movement artefact at the end of the slow wave activity, and at this point the patient starts singing (approximately 1.5 seconds before the end of this EEG section). (Time constant $=0.3$ seconds, $\mathrm{HF}=70 \mathrm{~Hz}$ ).

production" shows that all fragments (fig 3) had individual rhythms and metrics. The patient himself was surprised when he listened to his "songs" as he was not familiar either with the melody nor with the words. His medication was changed from phenytoin to carbamazepine, $1600 \mathrm{mg}$ a day (serum level were $41 \mathrm{ml} / \mathrm{l}$ ). This reduced his seizure frequency considerably and at follow up three months after discharge he had only had one attack.
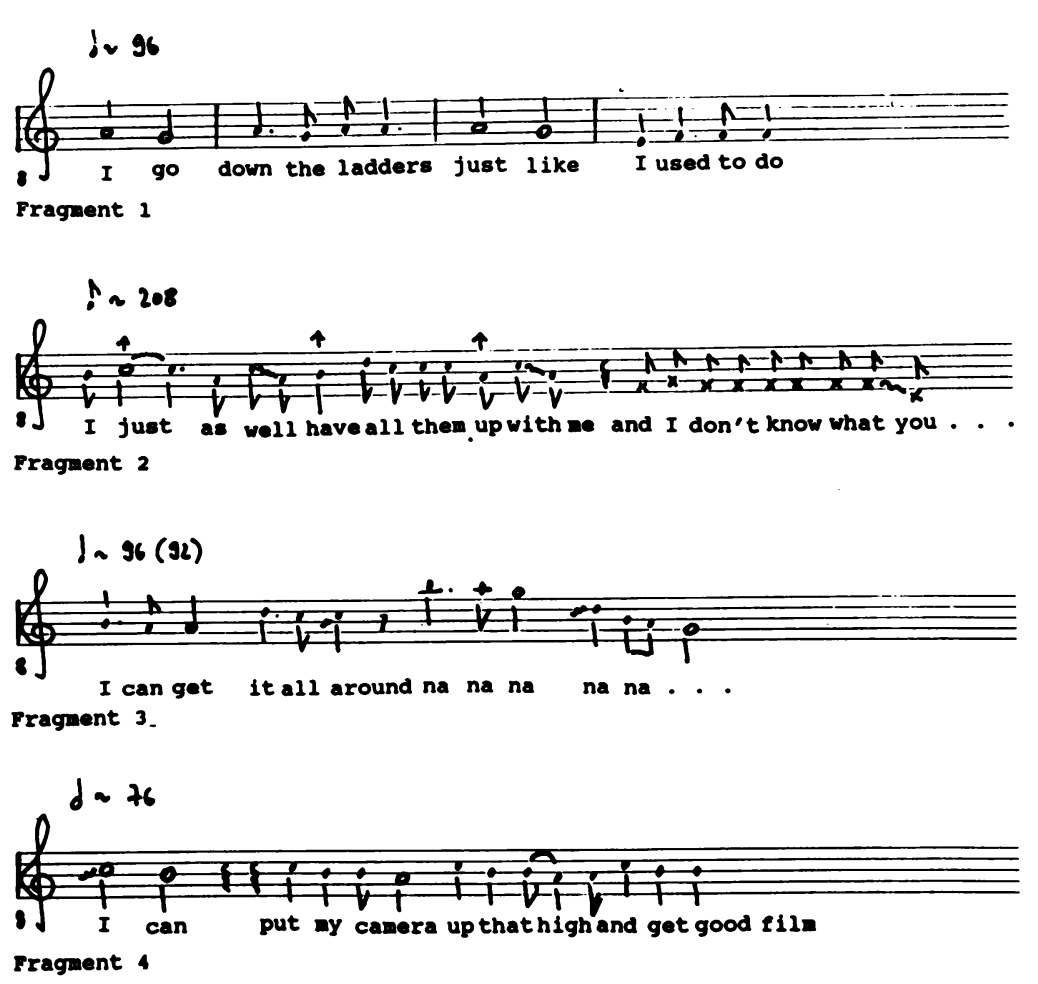

Figure 3 "The musical production" on four successive occasions. The figures refer to metre.
Discussion

Automatisms are defined as "More or less coordinated and adapted involuntary motor activity occurring during a state of clouding of consciousness either in the course of or after an epileptic seizure, usually followed by amnesia for the event".9 Although vocalisation and primitive sounds (for example, grunt, groan, screech, cry) commonly occur in the automatism of partial seizures of both frontal and temporal lobe origin, to our knowledge, no patient has been described in whom genuine song was produced. Our case provides an example of the highly complex behaviour which may occur as an epileptic "automatism". ${ }^{10}$ In our patient, the song was the predominant feature of the automatism and was preceded by axial stiffening with breath holding in inspiration and followed by fumbling activities. The four fragments of his "musical production" (fig 3) were melodious but had some features that were different from natural singing. The pitch was considered slightly higher and the strength of the sound appeared to be unduly forced. All fragments may be regarded as units consisting of individual colour of expression and metrics. Fragment two resembles "Sprechgesang" with it's slightly higher pitch compared with normal speech but with a similar rhythm.

No structural abnormality was found on CT scanning. The interictal EEG, however, frequently showed a right mid-temporal focal abnormality which was never seen on the left, providing strong evidence that the attacks arose in this area. Given the complexity of music and the physiological mechanisms involved in perception and production or the execution of music it is not surprising that the cerebral localisation of "musicality" remains elusive. Henschen ${ }^{11}$ suggested there were centres of singing, even specific centres for each musical instrument. Wertheim ${ }^{12}$ thought that expressive amusia was due to non-dominant lesions, as did Damasio and Damasio. ${ }^{13}$ Penfield and Perot $^{8}$ elicited hallucinations by stimulation in the temporal lobe, as did Gloor et al. ${ }^{14} \mathrm{Wieser}^{15}$ recorded a patient singing Portuguese songs as part of an ictal phenomenology, accompanied by EEG discharges in the right transverse gyrus of Heschl. Vidailhet et al $^{16}$ reported a patient with humming and a bifrontal meningioma. Sodium amytal procedures have shown clearly that without an intact right hemisphere, singing is not possible. ${ }^{317}$ Recently Creutzfeld and Ojemann ${ }^{18}$ recorded neuronal activity in the lateral temporal lobe with microelectrodes during epilepsy surgery, while patients listened to short pieces of music, and the changes were bilateral with no significant right left differences and with no topographical differences between superior, middle and inferior temporal gyri.

The rarity of singing in the automatism of an epileptic fit can be contrasted to the well documented cases of "musicogenic epilepsy", in which exposure to music may precipitate seizures; these cases have been the subject of a comprehensive review by Critchley. ${ }^{19}$ Musicogenic epilepsy can be considered a form 
of reflex epilepsy, the pathophysiological basis of which is quite unknown but Forster ${ }^{20}$ found some evidence that it may be a process of the dominant hemisphere.

The literature regarding expressive amusia and singing in particular suggests that the right hemisphere plays an important role. There was evidence too, in our patient, that his seizures originated from the right hemisphere but how can his "musical performance" be explained? The automatism of singing may be regarded as a release phenomenon, alternatively, as an activation of learned motor patterns or memories, in which case it is interesting that the musical production was unfamiliar to the patient when played back, and that the fragments differed on each of the four recorded attacks.

We are grateful to Dr John Morgan-Hughes for permission to report the patient, Sabine Meierkord (Berlin) for transcription report the patient, Sabine Meierkord (Berlin) for transcription
and musicological advice, and the Sir jules Thorn Charitable Trust for generous support of the video-EEG telemetry unit.

1 Botez M, Wertheim N. Expressive aphasia and amusia. Brain 1959;82:186-202.

2 McFarland HR, Fortin D. Amusia due to right temporoparietal infarct. Arch Neurol 1982;39:725-7.

3 Gordon $\mathrm{HW}$, Bogen JE. Hemispheric lateralization of singing after intracarotid sodium amylobarbitone. $J$ Neurol Neurosurg Psychiatry 1974;37:727-38.
4 Ross ED, Jossman PB, Bell B, Sabin T, Geschwind N. Musical hallucinations in deafness. JAMA 1975;231: 620-2.

5 Cascino GD, Adams RD. Brainstem auditory hallucinosis. Neurology 1986;36:1042-7.

6 Keshavan MS, Kahn EM, Barr J. Musical hallucinations following removal of a right frontal meningioma. $J$ Neurol Neurosurg Psychiatry 1988;51:1235-41.

7 Mulder DW, Daly D. Psychiatric symptoms associated with lesions of temporal lobe. JAMA 1952;150:173-6.

8 Penfield W, Perot $P$. The brains record of auditory and visual experience. A final summary and discussion. Brain 1963; 86:595-696.

9 Gastaut H. Dictionary of epilepsy. PI: Definitions. Geneva: World Health Organization, 1973

10 Sears TA. Some neural and mechanical aspects of singing. In: Critchley M, Henson RA, eds. Music and the brain. London: Heinemann, 1977:141-55.

11 Henschen SE. On the function of the right hemisphere of the brain in relation to speech, music and calculation. Brain brain in relation
$1926 ; 49: 110-23$.

12 Wertheim $\mathrm{N}$. Is there an anatomical localisation for musical faculties? In: Critchley M, Henson RA, eds. Music and the brain. London: Heinemann, 1977:282-97.

13 Damasio AR, Damasio $H$. Musical faculty and cerebral dominance. In: Critchley M, Henson RA, eds. Music and the brain. London: Heinemann, 1977:141-55.

14 Gloor $P$, Olivier A, Quesney LF, Andermann F, Horowitz S The role of the limbic system in experiential phenomena of temporal lobe epilepsy. Ann Neurol 1982;12:129-44.

15 Wieser HG. Temporal lobe or physchomotor status epilepticus. A case report. Electroencephalogr Clin Neurophysiol 1980;48:558-72.

16 Vidailhet $M$, Serdaru M, Agid Y. Singing in the brain: a new form of complex partial seizure? J Neurol Neurosurg Psychiatry 1989;52:1306.

17 Bogen JE, Gorden HW. Musical test for functional lateralization with intracarotid amobarbital. Nature 1971; 230:524-5.

18 Creutzfeld O, Ojemann G. Neuronal activity in the human lateral temporal lobe. Activity changes during music. Exp Brain Res 1989;77:490-8.

19 Critchley M. Musicogenic Epilepsy (I). The Beginnings. In Critchley M, Henson RA eds. Music and the brain. London: Heinemann 1977:344-53.

20 Forster FM. Reflex epilepsy, behavioural therapy and conditional reflexes. Springfield, Ill: Charles C Thomas, 1977. 